Check for updates

Cite this: Chem. Commun., 2020, 56, 11493

Received 24th July 2020

Accepted 21st August 2020

DOI: $10.1039 / \mathrm{d} 0 \mathrm{cc} 05049 \mathrm{k}$

rsc.li/chemcomm

\section{A visible light-mediated, decarboxylative, desulfonylative Smiles rearrangement for general arylethylamine syntheses $\uparrow$}

\author{
David M. Whalley, ${ }^{a b}$ Hung A. Duong ${ }^{{ }^{a}}$ and Michael F. Greaney (D) *b
}

\begin{abstract}
A decarboxylative, desulfonylative Smiles rearrangement is presented that employs activated-ester/energy transfer catalysis to decarboxylate $\beta$-amino acid derived starting materials at roomtemperature under visible light irradiation. The radical Smiles rearrangement gives a range of biologically active arylethylamine products highly relevant to the pharmaceutical industry, chemical biology and materials science. The reaction is then applied to the synthesis of a chiral unnatural amino acid, 2-thienylalanine, used in the treatment of phenylketonuria. We also show how the reaction can proceed under metal-free and catalyst-free conditions.
\end{abstract}

The desulfonylative Smiles rearrangement is a powerful arylation method that exploits easy to make sulfonamides, to forge more challenging $\mathrm{C}_{\mathrm{aryl}}-\mathrm{Csp}^{3}$ bonds via ipso-substitution (Scheme 1.1). ${ }^{1}$ The reaction often features mild and operationally simple conditions, creating versatile pathways to functionalized amino heteroarenes 3 with no requirement for stoichiometric arylmetals. The best exemplified arylations in this regime proceed through a 5 -membered transition state with where one or both of the two carbon centres illustrated in red are $\mathrm{sp}^{2}$ hybridised. ${ }^{2-5}$ Representative examples are shown in Scheme 1.2: seminal work in this area from Motherwell established the reaction for $\mathrm{Csp}^{2}$ radicals in biaryl synthesis, ${ }^{2 b}$ the Nevado group have developed an acrylamide system triggered by a wide range of radical conjugate additions, ${ }^{3 i, j, k}$ and our own laboratory have used sulfonamide addition to sp-carbons for carbanion aryl transfer. $^{3 b, c}$

Smiles reaction on $\mathrm{Csp}^{3}$-tethered substrates, by contrast, is far more limited in the literature, and represents a highly appealing target for method development. The product arylethylamines $\mathbf{3}$ are amongst the most privileged scaffolds in

\footnotetext{
${ }^{a}$ Institute of Chemical and Engineering Sciences (ICES) Agency for Science, Technology and Research (A*STAR), 8 Biomedical Grove, Neuros, \#07-01, 138665, Singapore.E-mail: duong_hung@ices.a-star.edu.sg

${ }^{b}$ School of Chemistry, The University of Manchester, Oxford Road, Manchester M13 9PL, UK. E-mail: michael.greaney@manchester.ac.uk $\dagger$ Electronic supplementary information (ESI) available. See DOI: 10.1039/ docc05049k
}

chemistry and biology, found in endogenous signalling molecules such as melatonin, adrenaline, serotonin and dopamine, and have been widely exploited in medicines for central nervous system (CNS) disorders (e.g. antidepressants agomelatine and venlafaxine, Parkinson's treatment baclofen, and stimulants such as amphetamine and Ritalin). ${ }^{6}$

A small number of aryl transfer routes to arylethylamines are known, including some of the earliest reports from Speckamp on the $\alpha$-halomethylpiperidinyl system., ${ }^{2,7}$ Zard established the reaction for xanthates $\mathbf{4}$, using thermal cleavage with a peroxide initiator to give the substituted arylethylamines $\mathbf{5}$ (Scheme 2.1). ${ }^{8}$ Recent work by Stephenson used the visible light SET oxidation of $p$-methoxystyrenes to trigger sulfonamide addition, followed by Smiles rearrangement to give 1,1diarylethylamines $\mathbf{8 .}^{3 a}$ Our laboratory has effected radical Smiles rearrangement using visible light-mediated addition of bromodifluoroacetate to alkenes 9, giving the gem-difluoro substituted arylethylamines $11 .{ }^{9}$ In most cases, the reaction design generates secondary radicals for desulfonylative Smiles

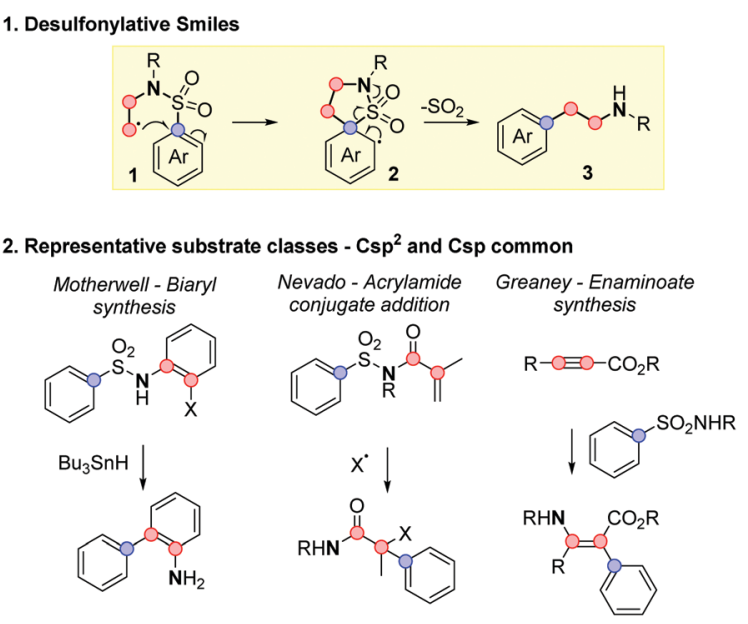

Scheme 1 Desulfonylative Smiles rearrangements to access arylethylamine structures. 
1. Previous work - arylethylamine synthesis

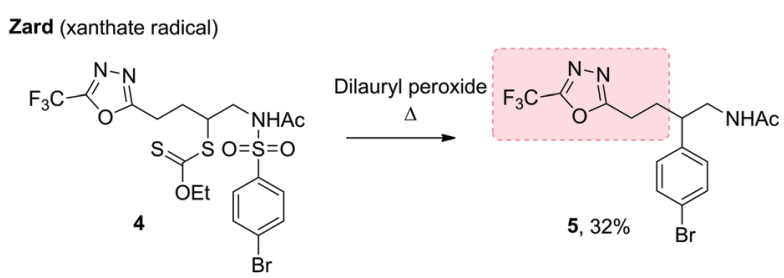

Stephenson (photoredox catalysis)

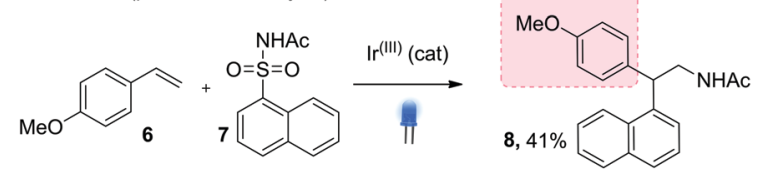

Greaney (electron-donor acceptor complex)

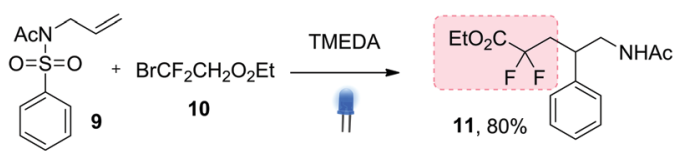

Reiser (photoredox catalysis)

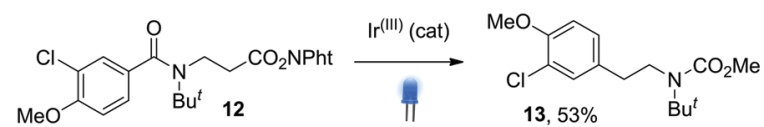

2: This work

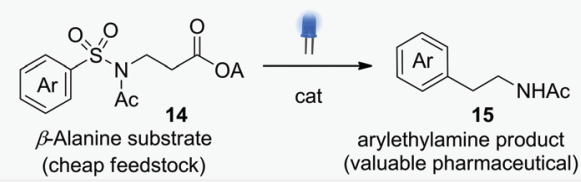

Scheme 2 Extrusion Smiles rearrangements to access arylethylamine structures.

rearrangement, producing branched products. A notable exception from Reiser and co-workers used decarbonylative Smiles rearrangement from the tert-butylated benzoylamides 12 to access the parent phenylethylamines $13 .^{5 c}$ The more demanding amide decarbonylation step necessitated an intramolecular single electron transfer mechanism, requiring electron rich migrating aryl groups for efficient reaction.

We were interested in establishing a general approach to unsubstituted and substituted arylethylamines under mild, catalytic conditions. Our reaction design is shown in Scheme 2.2 and represents the first example of a desulfonylative, decarboxylative Truce-Smiles rearrangement. The extrusion of $\mathrm{CO}_{2}$ provides expedient access to the key $\mathrm{Csp}^{3}$ radical species (1 in Scheme 1.1) and uses readily available amino acid starting materials 14, exploiting their low cost, high availability and in certain cases, enantiopurity. On the other hand, the extrusion of $\mathrm{SO}_{2}$ to irreversibly drive the Truce-Smiles rearrangement has proven to be an efficient means to incorporate a plethora of aryl species including electron rich and poor arene rings as well heterocycles. We hypothesised that the synergy of these two strategies would provide arylethylamine examples largely inaccessible by other reports in the field of Smiles chemistry.
Table 1 Oxime ester optimization ${ }^{a}$

\begin{tabular}{|c|c|c|c|}
\hline & S) & $\begin{array}{c}\frac{\left[\operatorname{lr}\left(\mathrm{dF}\left(\mathrm{CF}_{3}\right) \mathrm{ppy}\right)_{2}(\mathrm{dtbbpy})\right] \mathrm{PF} \mathrm{F}_{6}}{(1 \mathrm{~mol} \%)} \\
\text { THF [0.20 M], Blue LEDs, } \\
15 \text { h, r.t. }\end{array}$ & 17 \\
\hline Entry & $\mathrm{R}$ & $\mathrm{R}^{\prime}$ & Conversion $^{b}$ \\
\hline 1 & $\mathrm{Ph}$ & $\mathrm{Ph}$ & 41 \\
\hline 2 & $\mathrm{Ph}$ & $\mathrm{H}$ & 50 \\
\hline 3 & $\mathrm{H}$ & $p-\mathrm{ClC}_{6} \mathrm{H}_{4}$ & 45 \\
\hline 4 & $p-\mathrm{FC}_{6} \mathrm{H}_{4}$ & $p-\mathrm{FC}_{6} \mathrm{H}_{4}$ & 63 \\
\hline
\end{tabular}

We began by preparing a series of $\beta$-alanine oxime esters 16 (three steps, no purification of intermediates required, see ESI $\dagger$ ). Recent work from Glorius has used these moieties in the room-temperature decarboxylation of aliphatic carboxylic acids via visible light-mediated energy transfer catalysis. ${ }^{10}$ This approach is attractive as it removes the need for stoichiometric reductants, commonly necessary for redox-active phthalimide based strategies. ${ }^{11}$ We used thiophenes as the migrating arenes in our initial optimization studies, owing to their prevalence in pharmaceuticals $^{12}$ and their success in literature aryl transfer reactions (Table 1). ${ }^{3 a, g, 5 d}$ Using $\operatorname{Ir}\left(\mathrm{dF}\left(\mathrm{CF}_{3}\right) \mathrm{ppy}\right)_{2}(\mathrm{dtbbpy}) \mathrm{PF}_{6}$ as catalyst, we were delighted to observe successful reaction for various oxime esters, with the $p$-fluoro derivative giving the best conversion.

A screen of catalysts, solvents, and concentrations established the iridium photosensitizer $(1 \mathrm{~mol} \%)$ in a tetrahydrofuran (THF) solvent $0.08 \mathrm{M}$ under blue LED irradiation, successfully delivered the arylethylamine product in $56 \%$ yield (17a). Notably, we also found that we could lower the catalytic loading to $0.25 \mathrm{~mol} \%$ with only a small reduction in reaction efficiency (see ESI $\dagger$ ).

We explored the scope of the reaction for thiophenylethylamines, initially. Compound $\mathbf{1 6 b}$, containing the 3-chlorothiophene substituent, gave a substantially higher yield, possibly due to prevention of side-reactions through ortho addition to the thiophene. It was possible to carry out this reaction under metal free conditions using an organic thioxanthone photosensitizer (10 mol\%), albeit at reduced efficiency. Both the brominated and un-substituted thiophene rings reacted in moderate yield (17c and $\mathbf{1 7 d}$ ), along with the Boc-protected substrate $17 \mathbf{e}$, establishing an orthogonal nitrogen-protecting group pathway. ${ }^{14}$

Substitution on the ethyl backbone was easily tolerated, with the $\alpha$ and $\beta$-methyl substrates rearranging in excellent yield (17f and $\mathbf{1 7 g}$ ). Pleasingly, we were able to show for $\mathbf{1 7} \mathrm{g}$ that reaction occurred without racemization, with both $R$ and $S$ starting materials delivering the enantiopure heterocyclic amphetamine-type structures, biosteres of other biologically active amines. ${ }^{13}$

Moving away from thiophene, the transformation could facilitate the migration of phenyl rings, creating a collection of biologically active phenylethylamines $\mathbf{1 7 h}-\mathbf{1 7 0}$. Fluorinated aryl rings have gained much attention within the medicinal chemistry community and we were keen to demonstrate the applicability to 
our system. Hydrolysis products of $\mathbf{1 7 h} \mathbf{- 1 7} \mathbf{j}$ have all been used in the literature as components for pharmaceutically relevant compounds as well as active components in organic semiconductors. ${ }^{14}$ Whilst the unsubstituted phenyl ring proved to be an ineffective migrating group, 2-fluorophenylethylamine $\mathbf{1 7 h}$ could be incorporated with moderate yield by increasing the electrophilicity of the ipso position. This is further demonstrated in example 17i where both the 2 and 6 positions are blocked, preventing deleterious alkyl radical addition products. 2-Trifluoromethoxyphenyl $\mathbf{1 7 k}$ also acted as a good substrate for desulfonylative Smiles chemistry. ${ }^{15}$ Additional examples with 2-substitution included 17l, showing that we could incorporate anisyl rings in our chemistry, as well as meta substitution for further functionalisation of the arene system (17m). 1-Naphthylethylamine, a known tryptamine analogue, could be synthesized $(\mathbf{1 7 n})$, potentially opening up new synthetic routes to the antidepressant agomelatine. ${ }^{16}$ In accordance with other reports on radical ipso substitution, the reaction was tolerant of steric hindrance demonstrated with compound 17o, containing a mesityl ring. ${ }^{17}$
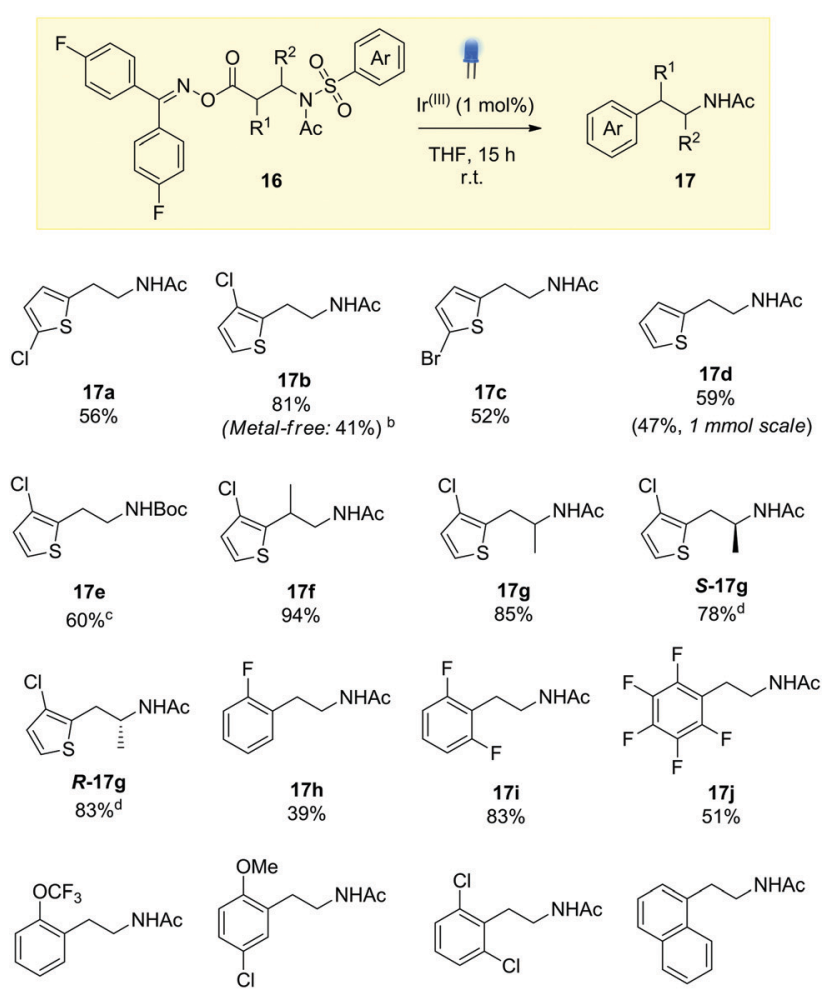

$17 \mathbf{k}$
$61 \%$
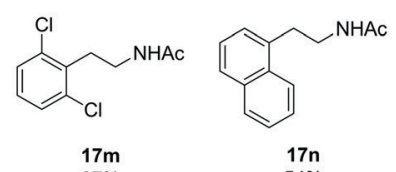

$77 \%$

$87 \%$

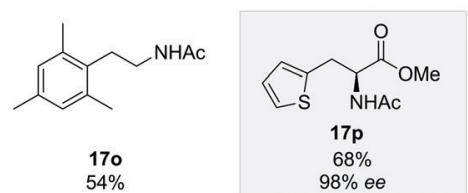

Scheme 3 Scope of the decarboxylative, desulfonylative Truce-Smiles rearrangement. ${ }^{a}{ }^{a} 0.20 \mathrm{mmol}$ scale, $\operatorname{Ir}(\mathrm{II})=\operatorname{Ir}(\mathrm{dF}(\mathrm{CF} 3) \mathrm{ppy})_{2}(\mathrm{dtbbpy}) \mathrm{PF}_{6}$, $2.5 \mathrm{~mL}$ THF. ${ }^{b} 10 \mathrm{~mol} \%$ thioxanthone catalyst, blue LED irradiation. ${ }^{c} \mathrm{NMR}$ yield using 1,3,5-trimethoxybenzene as an internal standard. ${ }^{d}$ No evidence of racemization, isolated as single enantiomers.

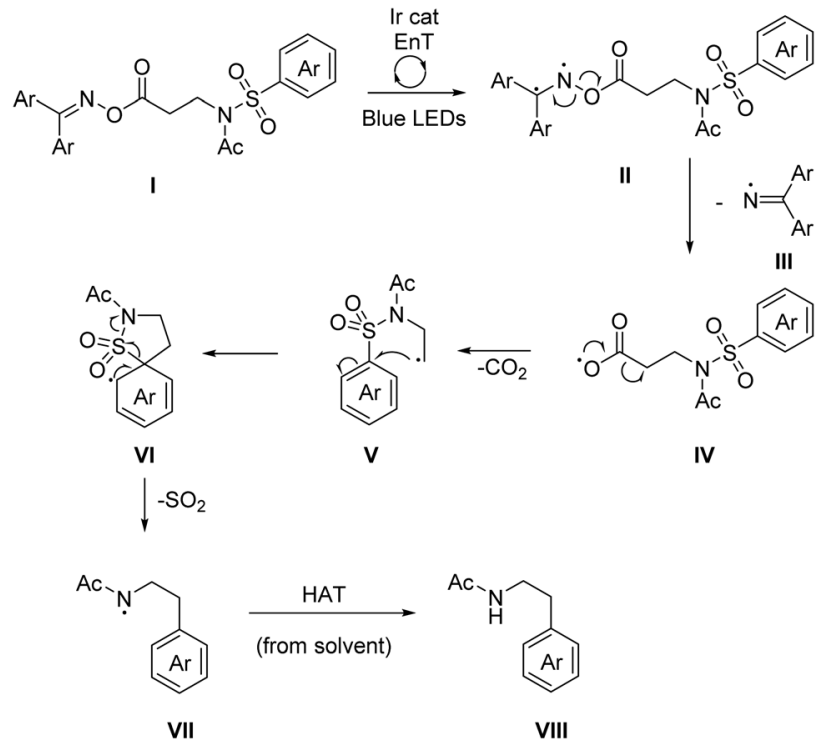

Scheme 4 Proposed mechanism of the decarboxylative, desulfonylative radical Truce-Smiles rearrangement. $\mathrm{Ar}=4-\mathrm{F}$-phenyl.

Finally, we were keen to demonstrate the methodology in the synthesis of a phenylalanine pharmaceutical. $\beta$-2-Thienylalanine has been used to treat infants with phenylketonuria, a genetic disorder resulting in the accumulation of phenylalanine in the blood, leading to brain damage if left untreated. ${ }^{18}$ Using the oxime ester derived from cheap and readily available L-methyl aspartate, photocatalytic Smiles rearrangement gave the protected $\beta$-2-thienylalanine $\mathbf{1 7 p}$ in $68 \%$ yield and $98 \%$ ee. Our approach compliments existing routes to this class of molecule, which use asymmetric Rh hydrogenation ${ }^{19}$ or enzymatic catalysis with phenylalanine ammonia lyase. ${ }^{20}$

The mechanism for the Smiles arylation likely begins with an energy transfer (EnT) event between the excited iridium catalyst and the activated imine I giving II, a diradical species (Scheme 4). Homolytic $\mathrm{N}-\mathrm{O}$ bond cleavage can then take place, releasing iminyl radical III which can be quenched via hydrogen atom abstraction (HAT), ${ }^{21}$ from the solvent's relatively weak $\mathrm{C}-\mathrm{H}$ bond $\left(\alpha-\mathrm{CH}\right.$ : BDE $\left.=385 \mathrm{~kJ} \mathrm{~mol}^{-1}\right) .{ }^{22}$ IV can spontaneously decarboxylate to give a primary alkyl radical $\mathbf{V} .^{23}$ This can then undergo a radical desulfonylative-Smiles rearrangement via ipso substitution, forming a spirocyclic intermediate VI, releasing $\mathrm{SO}_{2}$ to irreversibly drive the process to completion. One further HAT event between amidyl radical VII and the solvent gives the product, VIII. Owing to the inability of similarly reducing photocatalyst (see ESI $\dagger$ ) to yield any product, the absence of a suitable stoichiometric reductant, and the irreversible reduction

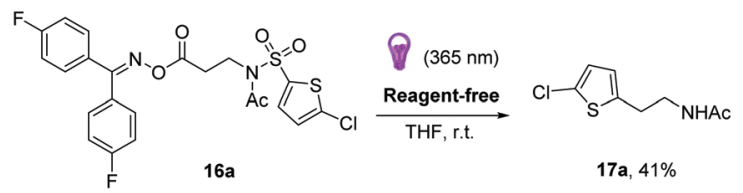

Scheme 5 Reagent-free desulfonylative, decarboxylative Truce-Smiles rearrangement. 
potential of $-2.0 \mathrm{~V}(v s \text {. SCE })^{10}$ we can rule out a photoredox mechanism as a viable pathway for $\mathrm{N}-\mathrm{O}$ bond cleavage. Furthermore the reaction can proceed with reasonable efficiency using the organic photosensitizer thioxanthone (17b, Scheme 3). In the dark no conversion is observed but under blue LED irradiation (catalyst free), a 20\% NMR yield of the product is observed.

In view of this last observation, we were intrigued to see if the reaction could be carried out catalyst-free by direct excitation of the oxime moiety using UVA radiation at room temperature (Scheme 5). This would allow for a reagent-free approach to $\mathrm{sp}^{3}-\mathrm{sp}^{2} \mathrm{C}-\mathrm{C}$ bond formation, at room temperature. We were pleased to find that we obtained a $41 \%$ NMR yield of the final product ( $c f$. example 17a, Scheme 3 ), indicating the viability of this approach. $^{24}$

In conclusion, we have developed a new decarboxylative, desulfonylative Truce-Smiles rearrangement enabled by visible light energy transfer catalysis. The reaction uses starting materials derived from commercially available $\beta$-amino acids, giving extensive control over the aryl species, ethyl chain substitution and amino protection for the synthesis of new arylethylamines. The reaction can be carried out metal-free and catalyst-free and applied to the synthesis of chiral unnatural amino acids.

\section{Conflicts of interest}

There are no conflicts to declare.

\section{Notes and references}

1 C. Holden and M. F. Greaney, Chem. - Eur. J., 2017, 23, 8992-9008. 2 Early work: $(a)$ R. Loven and W. N. Speckamp, Tetrahedron Lett., 1972, 13, 1567; (b) W. B. Motherwell and A. M. K. Pennell, Chem. Commun., 1991, 877.

3 Recent desulfonylative Smiles reports: (a) T. Monos, R. McAtee and C. Stephenson, Science, 2018, 361, 1369; (b) P. G. T. Rabet, S. Boyd and M. F. Greaney, Angew. Chem., Int. Ed., 2017, 56, 4183; (c) C. A. Holden, S. M. A. Sohel and M. F. Greaney, Angew. Chem., Int. Ed., 2016, 55, 2450; (d) E. Brachet, L. Marzo, M. Selkti, B. König and P. Belmont, Chem. Sci., 2016, 7, 5002; (e) S. Coulibali, T. Godou and S. Canesi, Org. Lett., 2016, 18, 4348; $(f)$ S. W. Crossley, R. M. Martinez, S. Guevara-Zuluaga and R. A. Shenvi, Org. Lett., 2016, 18, 2620; $(g)$ J. J. Douglas, H. Albright, M. J. Sevrin, K. P. Cole and C. R. J. Stephenson, Angew. Chem., Int. Ed., 2015, 54, 14898; (h) O. K. Rasheed, I. R. Hardcastle, J. Raftery and P. Quayle, Org. Biomol. Chem., 2015, 13, 8048; (i) N. Fuentes, W. Kong, L. FernandezSanchez, E. Merino and C. Nevado, J. Am. Chem. Soc., 2015, 137, 964; $(j)$ W. Kong, N. Fuentes, A. Garcia-Dominguez, E. Merino and C. Nevado, Angew. Chem., Int. Ed., 2015, 54, 2487; (k) W. Kong,
M. Casimiro, E. Merino and C. Nevado, J. Am. Chem. Soc., 2013, 135, 14480.

4 For desulfonylative Smiles that proceed through 4-membered transition states, see: $(a)$ M. W. Wilson, S. E. Ault-Justus, J. C. Hodges and J. R. Rubin, Tetrahedron, 1999, 55, 1647; (b) V. Lupi, M. Penso, F. Foschi, F. Gassa, V. Mihali and A. Tagliabue, Chem. Commun., 2009, 5012; (c) S. Johnson, E. Kovacs and M. F. Greaney, Chem. Commun., 2020, 56, 3222.

5 Recent non-desulfonylative Smiles examples: $(a)$ X. Chang, Q. Zhang and C. Guo, Org. Lett., 2019, 21, 4915; (b) J. Li, Z. Liu, S. Wu and Y. Chen, Org. Lett., 2019, 21, 2077; (c) C. Faderl, S. Budde, G. Kachkovskyi, D. Rackl and O. Reiser, J. Org. Chem., 2018, 83, 12192; (d) D. Alpers, K. P. Cole and C. R. J. Stephenson, Angew. Chem., Int. Ed., 2018, 12167; (e) D. L. Leonard, J. W. Ward and J. Clayden, Nature, 2018, 562, 105; $(f)$ R. Costil, Q. Lefebvre and J. Clayden, Angew. Chem., Int. Ed., 2017, 56, 14602; $(g)$ S.-F. Wang, X.-P. Cao and Y. Li, Angew. Chem., Int. Ed., 2017, 56, 13809; (h) R. Costil, H. J. A. Dale, N. Fey, G. Whitcombe, J. V. Matlock and J. Clayden, Angew. Chem., Int. Ed., 2017, 56, 12533; (i) D. JanssenMueller, S. Singha, F. Lied, K. Gottschalk and F. Glorius, Angew. Chem., Int. Ed., 2017, 56, 6276; $(j)$ S. S. Bhojgude, T. Roy, R. G. Gonnade and A. T. Biju, Org. Lett., 2016, 18, 5424.

6 S. Freeman and J. F. Adler, Eur. J. Med. Chem., 2002, 37, 527.

7 H. J. Köhler and W. N. Speckamp, J. Chem. Soc., Chem. Commun., 1980, 142; and references therein.

8 A. Gheorghe, B. Quiclet-Sire, X. Vila and S. Zard, Org. Lett., 2005, 7, 1653.

9 D. Whalley, H. Duong and M. Greaney, Chem. - Eur. J., 2019, 25, 1927.

10 T. Patra, S. Mukherjee, J. Ma, F. Strieth-Kalthoff and F. Glorius, Angew. Chem., Int. Ed., 2019, 58, 10514.

11 T. Patra and D. Maiti, Chem. - Eur. J., 2017, 23, 7382.

12 S. Pathania, R. K. Narang and R. K. Rawal, Eur. J. Med. Chem., 2019, 180, 486.

13 M. M. Goodman, G. W. Kabalka, J. Lee, G. W. Kabalka, R. C. Marks, Y. Liang and F. F. Knapp, J. Med. Chem., 1992, 35, 280.

14 R. Schmidt, J. H. Oh, Y. Sen Sun, M. Deppisch, A. M. Krause, K. Radacki, H. Braunschweig, M. Könemann, P. Erk and Z. Bao, et al., J. Am. Chem. Soc., 2009, 131, 6215.

15 K. Lee, Z. Lei, C. Morales-Rivera, P. Liu and M. Ngai, Org. Biomol. Chem., 2016, 14, 5599.

16 M. Dukat, C. Smith, K. Herrick-Davis, M. Teitler and R. A. Glennon, Bioorg. Med. Chem., 2004, 12, 2545.

17 M. L. E. N. Da Mata, W. B. Motherwell and F. Ujjainwalla, Tetrahedron Lett., 1997, 38, 137.

18 C. Krips and D. R. Lines, J. Paediatr. Child Health, 1972, 8, 318.

19 B. Mohar and M. Stephan, Adv. Synth. Catal., 2013, 355, 594.

20 C. Paizs, A. Katona and J. Rétey, Chem. - Eur. J., 2006, 12, 2739.

21 L. Chen, L. Guo, Z. Ma, Y. Gu, J. Zhang and X. Duan, J. Org. Chem., $2019,84,6475$.

22 C. Meyer, S. Hell, A. Misale, A. Trabanco and V. Gouverneur, Angew. Chem., Int. Ed., 2019, 58, 8829-8833.

23 (a) T. Patra, P. Bellotti, F. Strieth-Kalthoff and F. Glorius, Angew. Chem., Int. Ed., 2020, 59, 3172; (b) V. Soni, S. Lee, J. Kang, Y. Moon, H. Hwang, Y. You and E. Cho, ACS Catal., 2019, 9, 10454.

24 Reiser and co-workers reported an example of acetone-sensitised, UV-mediated Smiles reaction in their decarbonylative system, see ref. $5 c$. 